\title{
Hepatoprotective and antioxidative effect of ethanolic leaf extract of Langenaria breviflora (bitter gourd) on indomethacin-ulcerated rats.
}

\author{
Ajani E. O ${ }^{1 \mathrm{x}}$, Sabiu $\mathrm{S}^{1}$, Bamisaye, F. A ${ }^{1}$, Adenigba, B. V ${ }^{1}$, Awomoyi, D. D ${ }^{1}$, \\ Adeyanju M. M. \\ ${ }^{1}$ (Department of Biosciences and Biotechnology, Kwara State University, Malete, P. M. B. 1530, Ilorin, \\ Nigeria). \\ ${ }_{2}^{2}$ (Department of Biochemistry, Faculty of Basic Medical Sciences, Olabisi Onabanjo University, Ago-Iwoye, \\ Nigeria).
}

\begin{abstract}
Studies on the possibility of indomethacin-mediated hepatotoxicity have not received considerable attention over the years. The percentage of chronic users continue to rise, and its consequential hepatotoxic effect is encountered more frequently than ever. This study explored the effect of administration of ethanolic leaves extract of Lageneria breviflora on the hepatocyte and stomach of indomethacin-ulcerated rats. Ulceration was induced with indomethacin $(60 \mathrm{mg} / \mathrm{kg} \mathrm{b}$.wt). Ulcerated rats were then administered with 200 $\mathrm{mg} / \mathrm{kg}$ body weight of the extract for 21 days. At the end of the experiment, liver function indices and stomach oxidative status were evaluated. The study indicates that the extract significantly reduced $(p<0.05)$ serum activities of alanine aminotransferase, aspartate aminotransferase, alkaline phosphatase, gamma-glutamyl transpeptidase as well as albumin and total bilirubin concentrations. The stomach catalase and superoxide dismutase activities as well as the reduced glutathione level also improved significantly $(p<0.05)$ following treatment with the extract. Stomach lipid peroxidation in the ulcerated rats was also normalized by the extract. Data from this study indicates that the leaves of Lageneria breviflora possess hepatoprotective and antioxidative activities. Our findings suggest that the extract exerts its antiulcerogenic activity via antioxidative mechanism, there by stalling ravaging effects of reactive oxygen species.
\end{abstract}

Key words: Active principles, antioxidant, free radicals, hepatotoxicity, NSAIDS

\section{Introduction}

Reactive oxygen species (ROS) are a byproduct of normal metabolism and have roles in cell signaling and homeostasis. Mechanisms exist that regulate cellular levels of ROS, as their reactive nature may otherwise cause damage to key cellular components including DNA, protein, and lipids. A good number of drugs belonging to the class of non-steroidal anti-inflammatory drugs (NSAIDS) have been implicated in one form of cellular toxicity or another. These include acetaminophen, aspirin, diclofenac and indomethacin [1].

NSAIDs are widely used as antipyretic and anti-inflammation agents. They have also been shown to be effective and useful agents for a variety of diseases including rheumatic, musculoskeletal, and cardiovascular diseases [2]. However, their use is limited by their gastrointestinal toxicity via formation of ROS [3-4]. It has been proposed that NSAID-mediated gastrointestinal lesions involve the uncoupling of oxidative phosphorylation and inhibition of electron transport chain causing incomplete reduction of oxygen [1]. Specifically, indomethacin, a potent NSAID, has been reported to bind to a site near complex I and ubiquinone, thus facilitating events leading to ROS generation [5-6]. Subsequently, when the cellular antioxidant capacity is overwhelmed, mitochondrial aconitase is inhibited, resulting in the release of iron that reacts with $\mathrm{H}_{2} \mathrm{O}_{2}$, producing hydroxyl radical. This cascade of events amplifies oxidative stress whose consequential effect is manifested at various cellular/ and organ damage [7]. Oxidative stress-induced functional loss is well correlated with numerous disease states including cardiovascular, neurological, cancer, ageing processes, gastropathy [2] and is also implicated in a variety of drug-induced toxicities such as hepatotoxicity [8].

Antioxidative and free radical scavenging mechanism plays an important role in the protection against ROS mediated toxicities [9]. Over the past decade, interest in drugs derived from plants, especially the antioxidative ones, has increased appreciably [10]. In some African countries including Nigeria, a good percentage of the populace relies exclusively on plants as a source of medicine to complement and supplement the increasingly expensive orthodox medical services [11]. One of such plants finding applications in this respect is Langenaria breviflora.

Lagenaria breviflora, a perennial climber of the family Cucurbitaceae is a plant occurring from Senegal to the West Cameroons, and generally widespread in tropical Africa [12]. The whole fruit of the plant is used for the prevention and treatment of newcastle disease in poultry and measles in humans [13-15]. The potency of its 
fruits against a wide range of gastrointestinal disorders and measles in animal models and humans has been documented in West Africa [16]. Its broad spectrum antibacterial activity has also been reported [17]. Phytochemical analysis of its whole fruit revealed the presence of saponins, phenolic acids [18] and cucurbitacins [19-20]. Quite a number of cucurbitacins have been investigated for their cytotoxic [21], antiinflammatory [22] as well as hepato-protective and cardiovascular effects [19].

Although, literature is replicits with the medical properties of $L$. breviflora's fruit, there is paucity of information on the therapeutic efficacy of its leaf which is relatively abundant and available year round compared to the fruit. Interestingly, promising data from our laboratory on the bioactive principles and safety profile of its ethanolic leaf extract prompted this research. Accordingly, the present study was designed to evaluate its ethanolic leaves extract for possible antioxidative and hepatoprotective potential on indomethacin ulcerated rats.

\subsection{Chemicals and reagents}

\section{Methodology}

Assay kits for liver function indices and antioxidants were products of Randox Laboratories limited, United Kingdom. Indomethacin was procured from Kapit Pharmaceuticals Limited, Nigeria. Distilled water was obtained from the Biochemistry Laboratory, Kwara State University, Malete, Ilorin, Nigeria. Other chemicals and reagents were of analytical grade.

\subsection{Plant collection and authentication}

Fresh whole plant of Lagenaria breviflora comprising the leaves, fruits and roots were collected from farms in and around Oke Oyi, Ilorin, Kwara State, Nigeria. The plant was authenticated by a botanist at the Herbarium of Kwara State University, Malete, Nigeria, where a voucher specimen was also deposited.

\subsection{Experimental animals}

Wistar strain albino rats with a mean weight of $120.00 \pm 2.33 \mathrm{~g}$ were obtained from the Animal House of Kwara State University, Malete, Nigeria. The animals were kept in clean metallic cages placed in a wellventilated room with optimum condition (temperature: $23 \pm 1^{\circ} \mathrm{C}$, photoperiod: $12 \mathrm{~h}$ natural light and $12 \mathrm{~h}$ dark, relative humidity: $45-50 \%$ ). They were acclimatized to animal house conditions for ten days and were allowed free access to food and water ad libitum. The protocol of the experiment was in conformity with the National Research Council [23] and was approved by the Animal and Human Health Ethics Committee, College of Pure and Applied Sciences, Kwara State University, Malete, Nigeria.

\subsection{Preparation of ethanolic extracts}

Fresh leaves of L. breviflora were chopped into small pieces, air-dried at room temperature for 10 days to a constant weight and subsequently pulverized into fine powder used for the study. The powdered sample $(500 \mathrm{~g})$ was suspended in 4 litres of $70 \%$ ethanol for $24 \mathrm{hrs}$. The solution obtained was filtered (with Whatman No. 1 filter paper) and the resulting filtrate lyophilized to give $12.0 \mathrm{~g}$ of the residue, corresponding to a yield of $2.4 \%$. This was then stored in a dessicator for further use.

\subsection{Animal grouping and treatments}

Thirty two albino rats were randomized into four groups of eight rats each and were given the following treatments:

$\begin{array}{ll}\text { Groups } & \text { Treatment modes } \\ & \text { Distilled water administered (normal control). } \\ 2 & \text { Indomethacin administered (test control). } \\ 4 & \text { Pretreatment with L. breviflora extract followed by indomethacin administration. } \\ 4 & \text { Indomethacin administered followed by treatment with } L \text {. breviflora extract. }\end{array}$

Indomethacin administration into group 2-4 rats were carried out at $60 \mathrm{mg} / \mathrm{kg}$ b.wt. Prior to the administration of the extract, the rats were deprived of food for $18 \mathrm{hrs}$ but had access to clean drinking water ad libitum. Group 1 rats served as normal control and received only distilled water. Gastric ulceration in groups 24 rats were induced with indomethacin $(60 \mathrm{mg} / \mathrm{kg} \mathrm{b} . \mathrm{w})$ and were deprived of food but had free access to water $18 \mathrm{~h}$ before induction. Group 2 rats served as ulcerated control and received only indomethacin while those in group 3 were pre-treated with therapeutic dose of L. breviflora leaf extract $(200 \mathrm{mg} / \mathrm{kg} \mathrm{b.w})$ for 21 days prior to ulceration. Four hours after indomethacin administration, rats in groups 1-3 were sacrificed. Animals in group 4 were post-treated with same $200 \mathrm{mg} / \mathrm{kg}$ b.w dose of L. breviflora extract once daily for 21 days with administration commencing $4 \mathrm{~h}$ after indomethacin administration. On the twenty second day, rats in group 4 were sacrificed. All administrations were done orally with metal oropharyngeal cannula.

\subsection{Preparation of serum and stomach isolation}

At the end of each experimental period, the animals were humanely sacrificed under diethyl ether anaesthesia. The neck area was cleared of fur to expose the jugular vein which was sharply cut with sterile surgical blade for blood collection. An aliquot $(5 \mathrm{ml}$ ) of collected blood sample was centrifuged at $15000 \mathrm{rpm}$ 
for $15 \mathrm{~min}$. The clear supernatant was carefully aspirated with a Pasteur's pipette into sample bottles for estimation of serum enzymes against liver function tests. Stomachs excised from the rats were opened along the greater curvature and cleaned of its contents, blood and fats. They were subsequently preserved and homogenized in ice cold $0.1 \mathrm{M}$ phosphate buffer $(1: 4 \mathrm{w} / \mathrm{v}, \mathrm{pH} 7.4)$ and used for assay of antioxidants and peroxidation status.

\subsection{Assay of liver function and antioxidants parameters}

Adopting the procedure described by Reitman and Frankel [24], serum activities of aspartate aminotransferase (AST) and alanine aminotransferase (ALT) were determined. Activities of gamma-glutamyl transpeptidase (GGT) and alkaline phosphatase (ALP) were assayed by the methods of Szasz [25] and Rec GSCC [26] respectively. Albumin and total bilirubin concentrations were respectively determined using the methods of Doumas et al [27] and Jendrassik and Grof [28]. Activities of superoxide dismutase (SOD) and catalase (CAT) were assayed using the methods of Marklund and Marklund [29] and Sinha [30] respectively. Reduced glutathione (GSH) level was estimated based on the method of Habig et al [31]. Following the procedure described by Devasagayam and Tarachand [32], level of lipid peroxidation measured in terms of malondialdehyde (MDA) was determined in the stomach homogenate.

\subsection{Statistical analysis}

All data were subjected to one-way analysis of variance (ANOVA) using SPSS software package for windows (Version 16) and expressed as mean \pm standard deviation $(\mathrm{SEM})(\mathrm{n}=8)$. Significant difference between the treatment means was determined at 5\% confidence level using Duncan's Multiple Range Test.

\section{Results}

Table 1 shows the effect of leaf extract of Lagenaria breviflora on the activities of serum ALT, AST, ALP, GGT as well as concentrations of albumin and total bilirubin in rats. Administration of $60 \mathrm{mg} / \mathrm{kg} \mathrm{b}$.w. of indomethacin in the treatment groups for induction of gastric ulceration caused a significant $(\mathrm{p}<0.05)$ elevation in these parameters. This was however significantly $(\mathrm{p}<0.05)$ attenuated in both extract pre- and post-treated animals when compared to normal group.

Figures 1-4 revealed the effect of ethanolic leaf extract of L. breviflora on the gastric antioxidant status of the treated rats. Significant elevation $(p<0.05)$ was observed in the activities of SOD (1), CAT (2) and GSH (3) in the extract treated rats compared with normal control. Similarly, the concentration of MDA (4) was significantly reduced $(\mathrm{p}<0.05)$ following treatment with the extract.

\section{Discussion}

Studies on NSAIDS-induced hepatotoxicity have been outside the scope of most researchers, yet the number of chronic NSAIDS users continue to rise, and its consequential hepatotoxic effect is encountered more frequently than before [2]. This could be attributed to vulnerability of the liver to chemical injury due to its central proximity to the digestive tract as well as its marked ability to biotransform xenobiotics and excrete exogenous substances into bile. Numerous mechanisms of action have been proposed to mediate the toxic effects of NSAIDs like indomethacin on gastrointestinal epithelia and hepatocyte [33-35], but of particular interest in the present study is oxidative stress.

A probable way to prevent and manage oxidative-stress-induced toxicity is supplementing and boosting the antioxidant defense system of the body. Our preliminary finding on the phytochemical constituents of the extract revealed the presence of flavonoids, tannins, terpenoids, saponnins and phenolics [36]. These bioactive principles have been reported to promote good health and exhibit antioxidative potentials [37-38]. Thus, the present study examined the possible antioxidative and hepatoprotective effects of the extract on indomethacin ulcerated rats.

Measurement of liver enzyme activity has been described as a valuable tool in providing information on the effect and nature of pathological damage to the organ. Alteration in activity of liver marker enzymes like alkaline phosphatase (ALP), aspartate aminotransferase (AST), alanine aminotransferase (ALT) and GGT suggests a possible damage to the hepatocyte membrane and thus a compromised integrity and permeability of the membrane [39]. The significant elevation in the activities of serum ALT, AST, ALP, GGT as well as concentrations of albumin and total bilirubin following administration of $60 \mathrm{mg} / \mathrm{kg} \mathrm{b}$.w of indomethacin may be an indication of liver injury. This may be attributed to the generation of free radicals which trigger chains of reaction resulting in liver damage. The increase in serum activities of these enzymes might be due to their leakage into the circulatory system following altered permeability of hepatocyte membrane, reflecting a severe damage to the structural architecture of the liver [40]. These results are in conformity with earlier reports by Aithal and Day [41] and Bjornsson [42] where NSAIDs were reported to have generated free radicals and posed toxic effect on hepatocyte in rats. Conversely, the significant reduction in enzymes activity of rats treated with Lagenaria breviflora leaf extract suggest that the leaf was able to ameliorate the hepatotoxic effect of 
indomethacin on the liver cells of rats. Similarly, the observed significant increase in serum concentration of total bilirubin in indomethacin ulcerated rats could be due to defect on the sinusoidal surface of the hepatocytes involved in bilirubin uptake that sees to the active transport mediated secretion of conjugated bilirubin into bile. This might have resulted from loss of potential gradient of ions transversing hepatocytes membrane. This agrees with the earlier reports by Garcia et al [43] and Andrade et al [44] where, NSAIDs were reported to have caused increased serum bilirubin. Excretion of serum bilirubin from the body is reduced if the liver is damaged resulting in high concentration of this metabolite in the blood. Thus, the significantly reduced level of bilirubin in the serum of rats, pre- and post-treated with Lagenaria breviflora leaves extract signifies that the plant may be rich in substances involved in maintaining the structural integrity of the hepatocyte membrane. Also, the significant elevation of albumin concentration following ulceration is an indication of increased synthetic function of the liver. This might be a consequence of impaired hepato-cellular function in the indomethacin ulcerated rats. This trend was however significantly $(\mathrm{p}<0.05)$ attenuated compared to the normal control in the extract treated groups. The observed trends in the extract treated groups suggest its probable hepatoprotective ability.

Indomethacin has been reported to decrease the antioxidant status in animals via free radicals generation. Such event consequently results in overwhelmed antioxidant defense system in experimental animal model [1, 45-46]. An imbalance between free radicals production and antioxidant defense system results in oxidative stress which further deregulates cellular functions leading to pathological conditions. In the present study, the reduced activity of antioxidant enzymes in indomethacin-ulcerated rats is a clear manifestation of excessive formation of free radicals resulting in mucosa epithelia damage. However, the significant increase in their activities following treatment with ethanolic leaf extract of L. breviflora is an indication of antioxidant effect. The significantly increased specific SOD activity in rats treated with the extract depicts that SOD aided prevention of gastric ulcer by catalyzing the breakdown of highly reactive radical superoxide $\left(\mathrm{O}^{2-}\right)$ into oxygen and hydrogen peroxide [47-48]. In addition, the elevated activity of CAT and GSH level in the extract-treated rats further attest to the probable antioxidant activity of L. breviflora leaf extract. Chen et al. [49] and Sayanti et al. [45] have also reported enhancement of gastric mucosa integrity by CAT and GSH through increased prostaglandin synthesis.

Oxidative rout to a cell induces peroxidation of membrane-bound lipids whose toxic products cause damage to macromolecules. In the present study, the increased concentration of MDA in the stomach of indomethacin-ulcerated rats is suggestive of facilitated lipid peroxidation leading to tissue damage and failure of body's antioxidant defense mechanisms to prevent formation of excessive free radicals. It has been reported that indomethacin caused significant increase in gastric lipid peroxidation due to free radical injury in necrotic mucosa epithelia of rats $[1,50]$. The significantly reduced concentration of MDA in the stomach of L. breviflora leaf extract-treated rats indicates its possible antiperoxidative attribute and thus antioxidative potential.

Studies have shown that L. breviflora is rich in antioxidants and phytochemicals which promote good health $[18,38]$. Hence, the effect elicited by administration of the ethanolic leaf extract of the plant may be attributed to its electron donating potential to form stable products and consequently halting free radicals chain reaction. The effect of antioxidants in modulating oxidative damage is opined to have reduced cancer incidence and also prevent cellular damage. Natural antioxidants have also been studied to be vitamins (carotenoids, ascorbic acid, tocopherol and their derivatives) and phytochemicals (flavonoids, saponins, phenols) [51]. The vitamins and phytochemical constituents of L. breviflora are considerably high and have been reported to enhance its therapeutic attribute [52]. This might have contributed to the modulatory effect displayed in the extract treated rats. This is in agreement with the submission of Sabiu et al [40] that vitamins and phytochemicals present in plants scavenges toxic load on the liver by binding to various harmful substances.

\section{Conclusion}

The restoration of cellular insults on the assayed parameters caused by indomethacin through treatment with ethanolic leaf extract of Lagenria breviflora may be an indication of its inherent hepatoprotective and antioxidant attributes in rats. Efforts are ongoing to isolate and characterize the active principle(s) responsible for the observed trait in the plant and make such a novel antioxidant candidate against drug-induced cellular toxicities.

\section{References}

[1]. Y. Hong, P. Xingchang, S. Zhixiu, W. Shaokang, Y. Ligang and S. Guiju, Protective Effect of Wheat Peptides against Indomethacin-Induced Oxidative Stress in IEC-6 Cells. Nutrients, 6, 2014, 564-574; doi:10.3390/nu6020564

[2]. Dae Y.C, Jin I.K., Soo-Heon P., Jae K.K. (2014). Proanthocyanidin from Grape Seed Extracts Protects Indomethacin-Induced Small Intestinal Mucosal Injury. Gastroenter Res Pract, 14: 618-626.

[3]. E. Bjornsson, Review article: drug-induced liver injury in clinical practice. Alimen Pharmacology Therapeutics, 32, $2013,3-13$.

[4]. Jarupongprapa S., Ussavasodhi P., Katchamart W. (2013). Comparison of gastrointestinal adverse effects between cyclooxygenase2 inhibitors and non-selective, non-steroidal anti-inflammatory drugs plus proton pump inhibitors: A systematic review and metaanalysis. J Gastroenterol, 48, 830-838. 
[5]. H. S. Kang, J. Ock, H. J. Lee, Y. J. Lee, B. M. Kwon and S. H. Hong, Early growth response Protein-1-upregulation and nuclear translocation by 2'-benzoyloxycinnamaldehyde induces prostate cancer cell death, Cancer Letter, 329, 2013, 217-227.

[6]. V. Vaish, H. Piplani, C. Rana, K. Vaiphei, and S. N. Sanyal, NSAIDs may regulate EGR-1- mediated induction of reactive oxygen species and non-steroidal anti-inflammatory drug-induced gene (NAG)-1 to initiate intrinsic pathway of apoptosis for the chemoprevention of colorectal cancer, Molecular Cell Biochemistry, 378, 2013, 47-64.

[7]. M. Valko, D. Leibfritz, J. Moncol, M. T. D. Cronin, M. Mazur and J. Telser, Free radicals and antioxidants in normal physiological functions and human disease, International Journal of Biochemistray and Cell Biology, 39, 2007, 44-84.

[8]. O. O. Ogunlabi, B. O. Adegbesan, O. B. Sumaoya and E. O. Ajani, Modulating effects of Allium sativum (garlic) extract in monosodium glutamate (Ajinomoto) induced injuries in rats, Medicinal Plants, 6(1), 2014, 48- 52.

[9]. 9. S. Sabiu and A. M. Wudil, Comparative effects of Telfaira occidentalis and Vernonia amygdalina on Garlic-induced Hepatotoxicity in rats, Biological and Environmental Sciences Journal for the Tropics (BEST). 8(4), 2011, 193-197

[10]. Y. Z. Shu, Recent natural products based drug development: a pharmaceutical industry perspective, Journal of Natural Product, 61, 1998, 1053-107. PMID: 9722499.

[11]. T. R. Fasola and A. Egunyomi, Nigerian usage of bark in phytomedicine. Ethnobotany Research Application, 3, 2005, 73-77.

[12]. O. A. Oridupa, A. B. Saba and L. K. Sulaiman, Preliminary report on the antiviral activity of the ethanolic fruit extract of Lagenaria breviflora Roberts on Newcastle Disease virus, Tropical Veterinary, 29 (1), 2011, 22-33.

[13]. M. Yasuyuki, M. Patrick, F. Hiroshi and M. Hiroko, Diversity of landraces of the white- flowered Gourd (Lagenaria siceraria) and its wild relatives in Kenya, Genet Research of Crop Evolution 52, 2005, 737-747.

[14]. S. H. Hanno, S. R. Christopher and A. Susanne, Gourds afloat adapted phytogeny reveals an Asian origin Rev Biology Tropics, 61 (1), 2009, 281-290.

[15]. A. A. Adedapo and B. O. Bankole, Ethnoveterinary survey of poultry management in some selected farms in Ibadan, Nigeria. Recent Progress, Medicinal Plant, 31, 2011, 305-316.

[16]. E. B. Sonaiya, Family poultry and food security: Research requirements in science, technology and socioeconomics. phytochemical screening of pignut (Jatrophas curcas Linn.) on some pathogenic bacteria. Journal of Medicinal Plants Research, 5(7), 2009, 12611264

[17]. O. A. Tomori, A. B. Saba and H. O. Dada-Adegbola, Antibacterial activity of ethanolic extract of whole fruit of Lagenaria breviflora Robert, Journal Animal Vet Advances, 6(5), 2007, 752-757.

[18]. A. A. Elujoba, A. F. Fell and P. A. Linley, Chromatographic and spectroscopic analysis of bound and unbound phenolic acids in Lagenaria breviflora fruit, Journal of Pharmaceutical Biomedical Anal, 9(9), 1999, 711-715.

[19]. M. Miro, Cucurbitacins and their pharmacological effects. Phytotherapy Research, 9, 1995, 159-168.

[20]. N. Wakimoto, D. Yin, J. O'Kelly, T. Haritunians, B. Karlan, J. Said, H. Xing and H. P. Koeffler, Science of Cancer, 99 (9), 2008, $1793-1797$.

[21]. N. P. Seeram, B. Jayaprakasam and M. G. Nair, Anticancer and anti-inflammatory activities of cucurbitacins from Cucurbita andreana. Cancer Letter, 189, 2007, 11-16

[22]. J. M. Escandell, M. C. Recio, S. Manez, R. M. Giner, M. C. Nicola's and J. L. Ri'os, Cucurbitacin R reduces the inflammation and bone damage associated with adjuvant arthritis in Lewis rats, American Journal of Phytomedicine, 20, 2007, 324-331.

[23]. National Research Council, Guide for the Care and Use of Laboratory Animals, National Academy Press, Washington, DC, 1999.

[24]. S. Reitman and S. Frankel, A colorimetric method for the determination of serum Glutamic- oxaloacetate and Glutamic-pyruvate Transaminase. American Journal of Clinical Pathology, 28, 1957, 56-61.

[25]. G. Szasz, Determination of GGT activity, Methods of Enzymatic Analysis, 2, 1974, 715 - 720

[26]. Rec, GSCC, Optimised standard colorimetric methods, Journal of Clinical Chemmistry and Clinical Biochemistry, 10, $1972,182$.

[27]. B. T. Doumas, W. A. Watson and H. G. Biggs, Albumin standards and the measurement of serum albumin with bomocresol green, Clin Chim Acta, 31, 1971, 87-96.

[28]. Jendrassik L, Grof P. (1938). A colorimetric method for the determination of direct and total bilirubin. Biol Chem, 297: 81

[29]. S. Marklund and G. Marklund, Involvement of superoxide anion radical in the autooxidation of pyrogallol and a convenient assay for superoxide dismutase, European Journal of Biochemistry, 47, 1974, 469-474.

[30]. A. K. Sinha, Colorimetric assay of catalase, Analytical Biochemistry, 47, 1972, 389-394.

[31]. W. H. Habig, M. J. Pabst and W. B. Jakoby, Glutathione-s-transferases, The first enzymatic step in mercapturic acid formation, Journal Biological Chemistry, 249, 1974, 7130-7139.

[32]. T. P. Devasagayam and U. Tarachand, Decreased lipid peroxidation in the rat kidney during gestation, Biochemistry Biophysics Research Communication, 145, 1987, 134-138.

[33]. T. Cochran, J. Stefanko, C. Moore and R. Saik, Dimethyl sulphoxide protection against gastric stress ulceration, Current Surgery, 40, 1987, 435-437.

[34]. H. J. Zimmerman, Update on hepatotoxicity due to classes of drugs in common clinical use: non-steroidal drugs, anti-inflammatory drugs, antibiotics, anti-hypertensives and cardiac and psychotropic agents, Semin Liver Disease, 10, 1990, 322-338.

[35]. K. Biswas, U. Bandyopadhyay, I. Chattopadhyay, A. Varadaraj, E. Ali and R. K. Banerjee, A novel antioxidant and antiapoptotic role of omeprazole to block gastric ulcer through scavenging of hydroxyl radical, Journal Biological Chemistry, 278, 2003, 1099311001 .

[36]. E. O. Ajani, S. Sabiu, F. A. Bamisaye and B. A. Salau, Evaluation of The Acute and Sub-acute Toxicity Effect of Ethanolic Leaves Extract Of Lagenaria breviflora (Bitter gourd) On Hepatic and Renal Function of Rats, European Journal of Medicinal plant, 2014 (in press)

[37]. N. Okarter, C. Liu, M. E. Sorrells and R. H. Liu, Phytochemical content and antioxidant activity of six diverse varieties of whole wheat, Food Chemistry, 119(1), 2009, 249-257.

[38]. S. A. Onasanwo, N. Singh, A. B. Saba, A.A. Oyagbemi, O. A. Oridupa and G. Palit, Anti- ulcerogenic and in vitro antioxidant activities of Lagenaria breviflora (LB) whole fruit ethanolic extract in laboratory animals, Pharmacognosy Research, 3, 2011, 2-8.

[39]. T. O. Sunmonu and O. B. Oloyede, Biochemical assessment of the effects of crude oil contaminated catfish (Clarias gariepinus) on the hepatocytes and performance of rat, African Journal of Biochemistry Research, 1(5), 2007, 83-89.

[40]. S. Sabiu, A. M. Wudil and T. O. Sunmonu, Combined administration of Telfaira occidentalis and Vernonia amygdalina leaf powders ameliorates Garlic-induced hepatotoxicity in Wistar rats. Pharmacologia, 5(5), 2014, 191-198

[41]. G. P. Aithal and C. P. Day, Nonsteroidal anti-inflammatory drug-induced hepatotoxicity. Clinical Liver Disease, 11, 2007, 563-575.

[42]. I. Bjarnason, Gastrointestinal safety of NSAIDs and over-the-counter analgesics. International Journal of Clinical Practice, 67, 2013, 37-42.

[43]. R. L. A. García, R. Williams, L. E. Derby, A. D. Dean and H. Jick, Acute liver injury associated with nonsteroidal antiinflammatory drugs and the role of risk factors, Archives Internal Medicine, 154, 1994, 311-316 
[44]. R. J. Andrade, M. I. Lucena, M. C. Fernández, G. Pelaez, K. Pachkoria, E. García-Ruiz, B. García-Muñoz, R. González-Grande, A. Pizarro and J. A. Durán, Drug-induced liver injury: an analysis of 461 incidences submitted to the Spanish registry over a 10 -year period. Gastroenterology, 129, 2005, 512-521.

[45]. B. Sayanti, R. C. Susri, C. Subrata and K. B. Sandip, Healing Properties of Some Indian Medicinal Plants against IndomethacinInduced Gastric Ulceration of Rats, Journal of Clinical Biochemistry and Nutrition, 41(2), 2007, 106-114.

[46]. G. I. Gege-Adebayo, V. U. Igbokwe, M. O. Shafe, C. O. Akintayo and D. I. Mbaka, Anti-ulcer effect of ocimum gratissimum on indomethacin induced ulcer and percentage of superoxide dismutase on wistar rats. Journal of Medicine and Medical Science, 4(1), 2013, 8-12

[47]. I. Zeiko, T. Mariam and R. Folz, Superoxide dismutase multigene family: a comparison of the CuZn-SOD (SOD1), Mn-SOD (SOD2) and EC-Sod (SOD3) genes structures, evolution and expression, Free Radical Protol Medicine, 33(3), $2002: 337-349$.

[48]. H. Gehen, K. A. H. Medy and S. A. Rauuia, Gastroprotective effect of simvastratin against indomethacin-induced gastric ulcer in rats: role of nitric oxide and prostaglandins, European Journal of Pharmacology, 607, 2009: 188-193.

[49]. G. Chen, M. Kamal, R. Hannon and T. D. Warner, Regulation of cyclooxygenase gene expression in rats smooth muscle cells by catalase, Biochemical Pharmacology, 55, 1998, 1621-1631.

[50]. Y. Raji, W. A. Oyeyemi, S. T. Shittu and A. F. Bolarinwa, Gastro-protective effect of methanol extract of Ficus asperifolia bark on indomethacin-induced gastric ulcer in rats, Nigerian Journal of Physiological Science, 26(1), 2011, 43-48.

Hill A.F. (1952). Economic Botany. A textbook of useful plants and plant products In suppression of Tumor Necrosis Factor in T Lymphocytes and Macrophages. 2nd ed. McGraw- Hill Book Company Inc, New York. .J Pharmacol Exp, Therap. 320: 581-590.

Table 1: Serum activities and levels of some liver function indices in indomethacin ulcerated rats administered

\begin{tabular}{|l|l|l|l|l|l|l|l|}
\hline Group & Treatment & ALT (U/L) & AST (U/L) & ALP (U/L) & GGT (U/L) & $\begin{array}{l}\text { Albumin } \\
(\mathrm{g} / \mathrm{dl})\end{array}$ & $\begin{array}{l}\text { Total } \\
\text { bilirubin } \\
(\mathrm{mg} / \mathrm{dl})\end{array}$ \\
\hline 1 & $\begin{array}{l}\text { Distilled water } \\
\text { control) }\end{array}$ & $49.67 \pm 6.77^{\mathrm{a}}$ & $17.00 \pm 0.01^{\mathrm{a}}$ & $324.75 \pm 23.86^{\mathrm{a}}$ & $72.02 \pm 8.55^{\mathrm{a}}$ & $19.99 \pm 1.77^{\mathrm{a}}$ & $6.65 \pm 0.72^{\mathrm{a}}$ \\
\hline 2 & Indomethacin & $70.50 \pm 3.72^{\mathrm{b}}$ & $22.20 \pm 0.03^{\mathrm{b}}$ & $358.10 \pm 24.26^{\mathrm{b}}$ & $95.15 \pm 5.24^{\mathrm{b}}$ & $24.08 \pm 0.23^{\mathrm{b}}$ & $8.16 \pm 0.49^{\mathrm{b}}$ \\
\hline 3 & $\begin{array}{l}\text { Extract, then } \\
\text { Indomethacin }\end{array}$ & $53.42 \pm 6.59^{\mathrm{a}}$ & $15.60 \pm 0.01^{\mathrm{a}}$ & $293.06 \pm 18.31^{\mathrm{a}}$ & $53.85 \pm 0.41^{\mathrm{a}}$ & $14.17 \pm 0.20^{\mathrm{a}}$ & $6.28 \pm 0.91^{\mathrm{a}}$ \\
\hline 4 & $\begin{array}{l}\text { Indomethacin, } \\
\text { then extract }\end{array}$ & $59.50 \pm 3.89^{\mathrm{a}}$ & $18.00 \pm 0.04^{\mathrm{a}}$ & $310.95 \pm 13.66^{\mathrm{a}}$ & $57.03 \pm 0.36^{\mathrm{a}}$ & $16.02 \pm 2.56^{\mathrm{a}}$ & $7.16 \pm 0.41^{\mathrm{a}}$ \\
\hline
\end{tabular}

Values with different superscripts along the same column for each parameter are significantly different $(\mathrm{P}<$ $0.05)$.

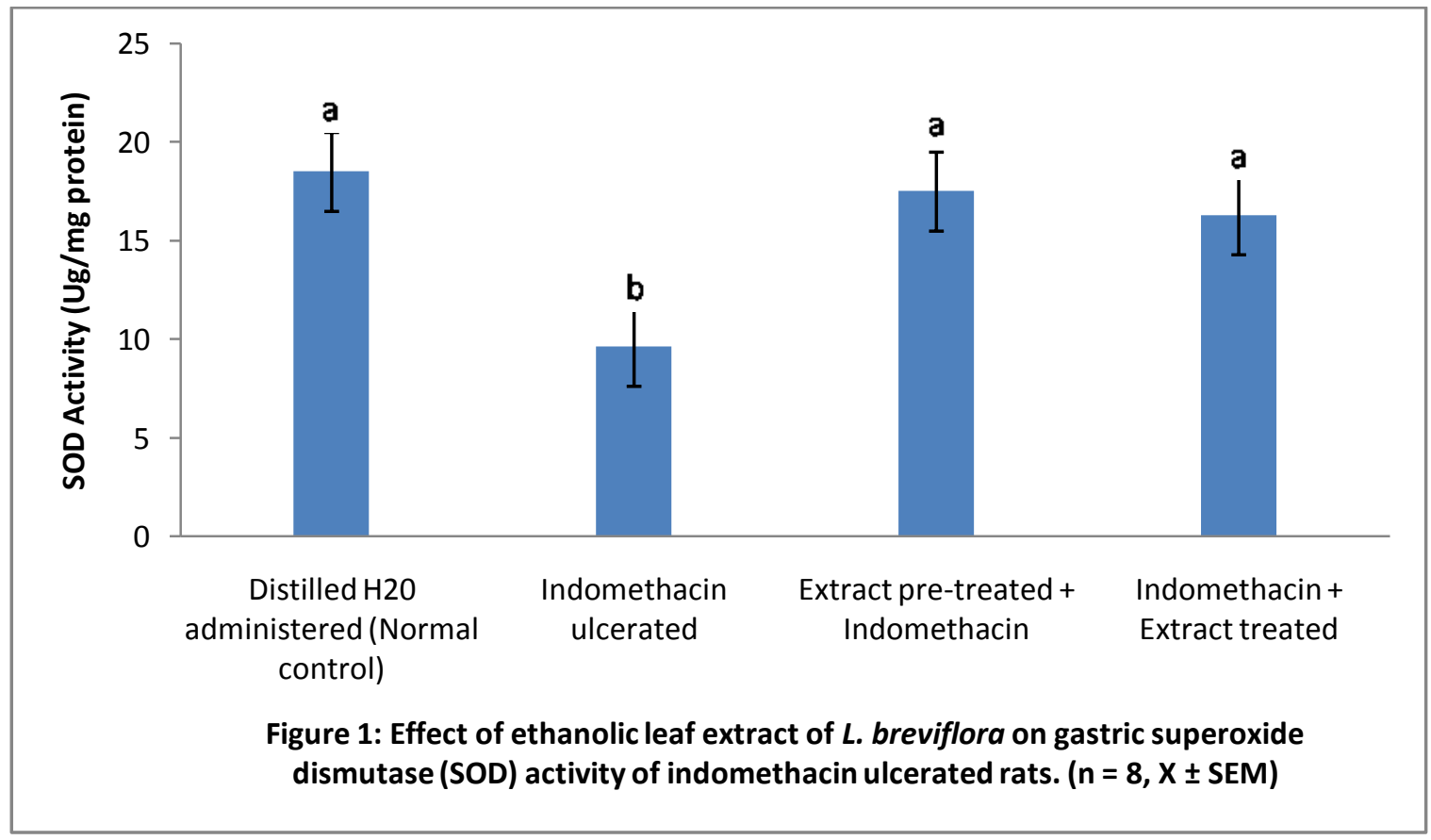

Bars with different superscripts for the parameter are significantly different $(\mathrm{P}<0.05)$. 


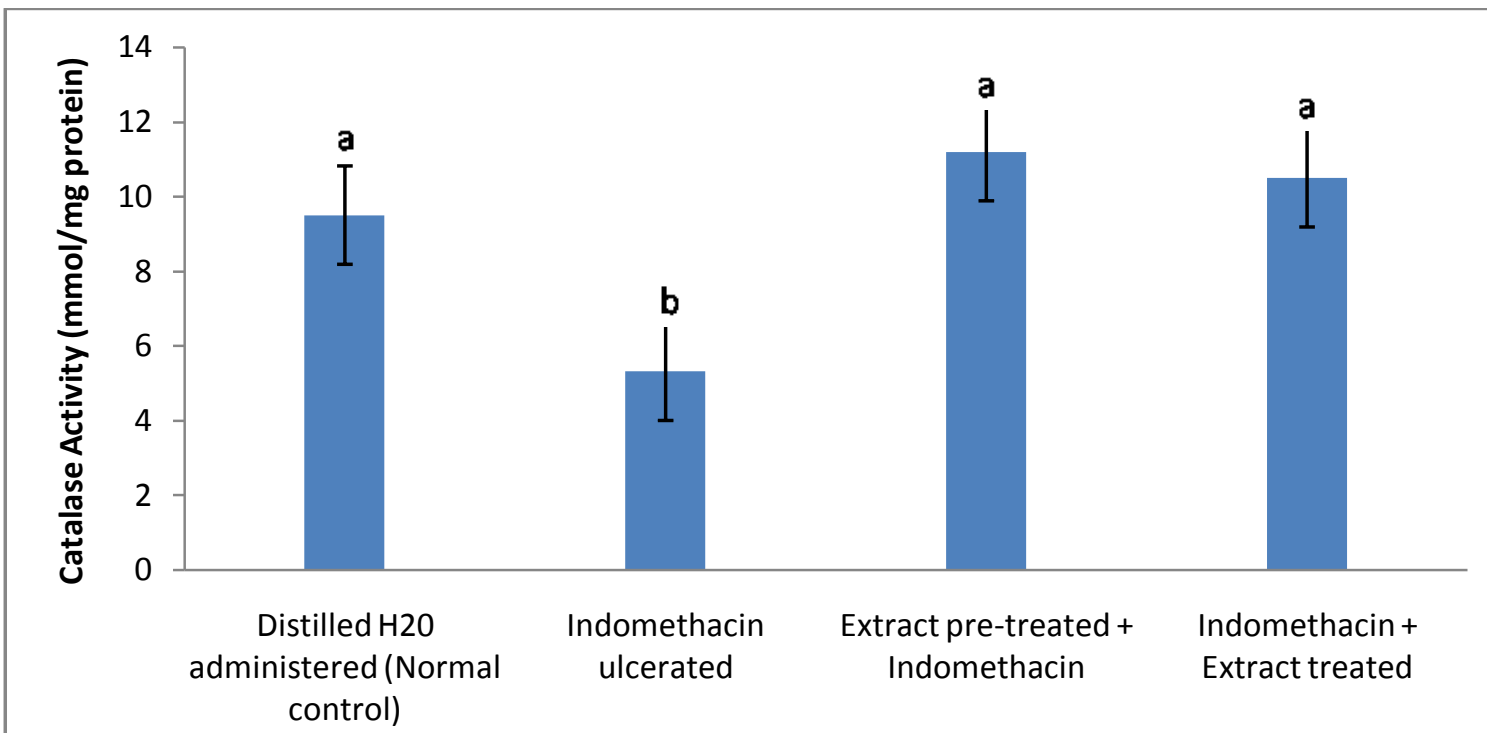

Figure 2: Effect of ethanolic leaf extract of $L$. breviflora on gastric catalase activity of indomethacin ulcerated rats. $(n=8, X \pm$ SEM)

Bars with different superscripts for the parameter are significantly different $(\mathrm{P}<0.05)$.

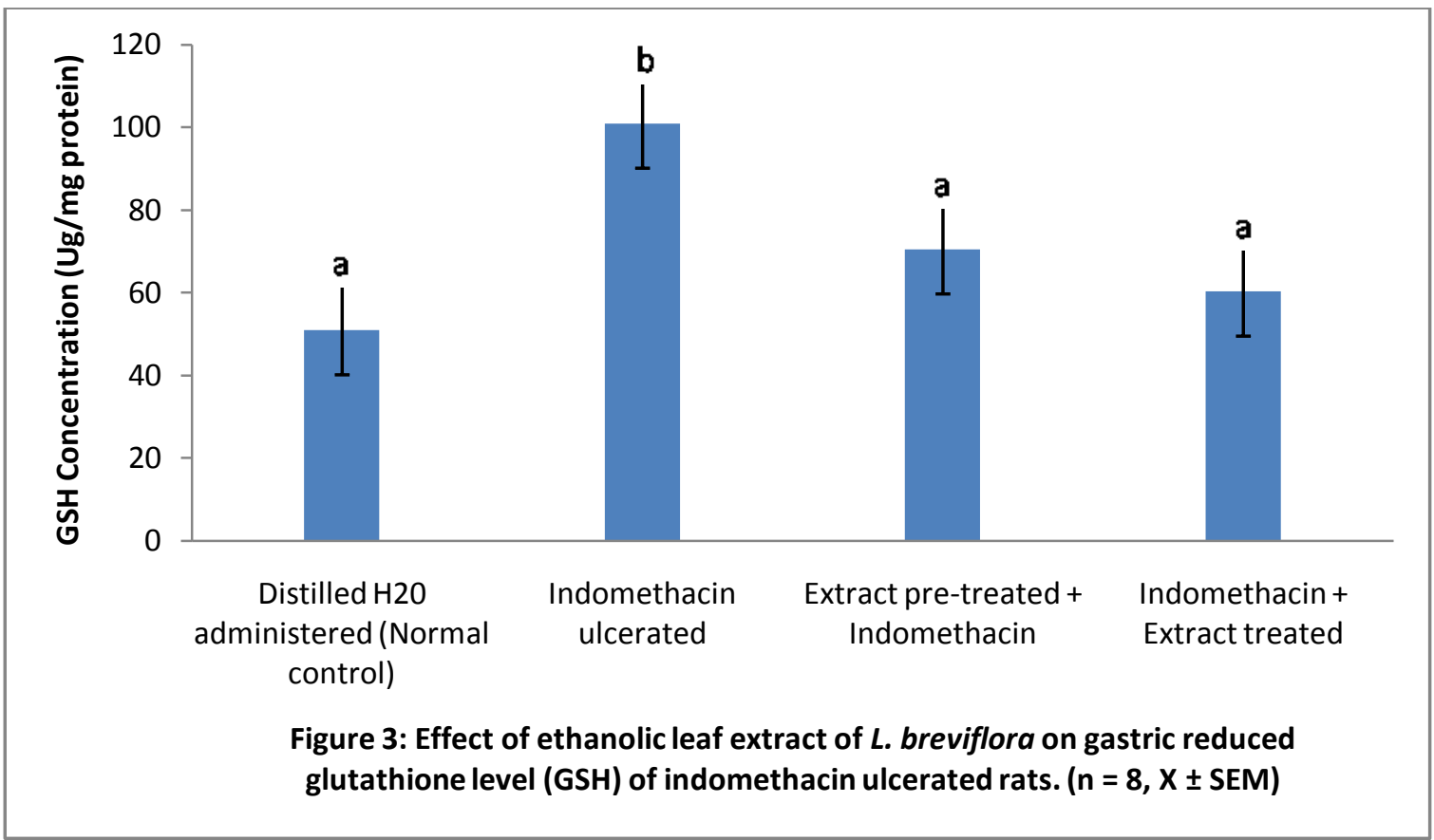

Bars with different superscripts for the parameter are significantly different $(\mathrm{P}<0.05)$. 


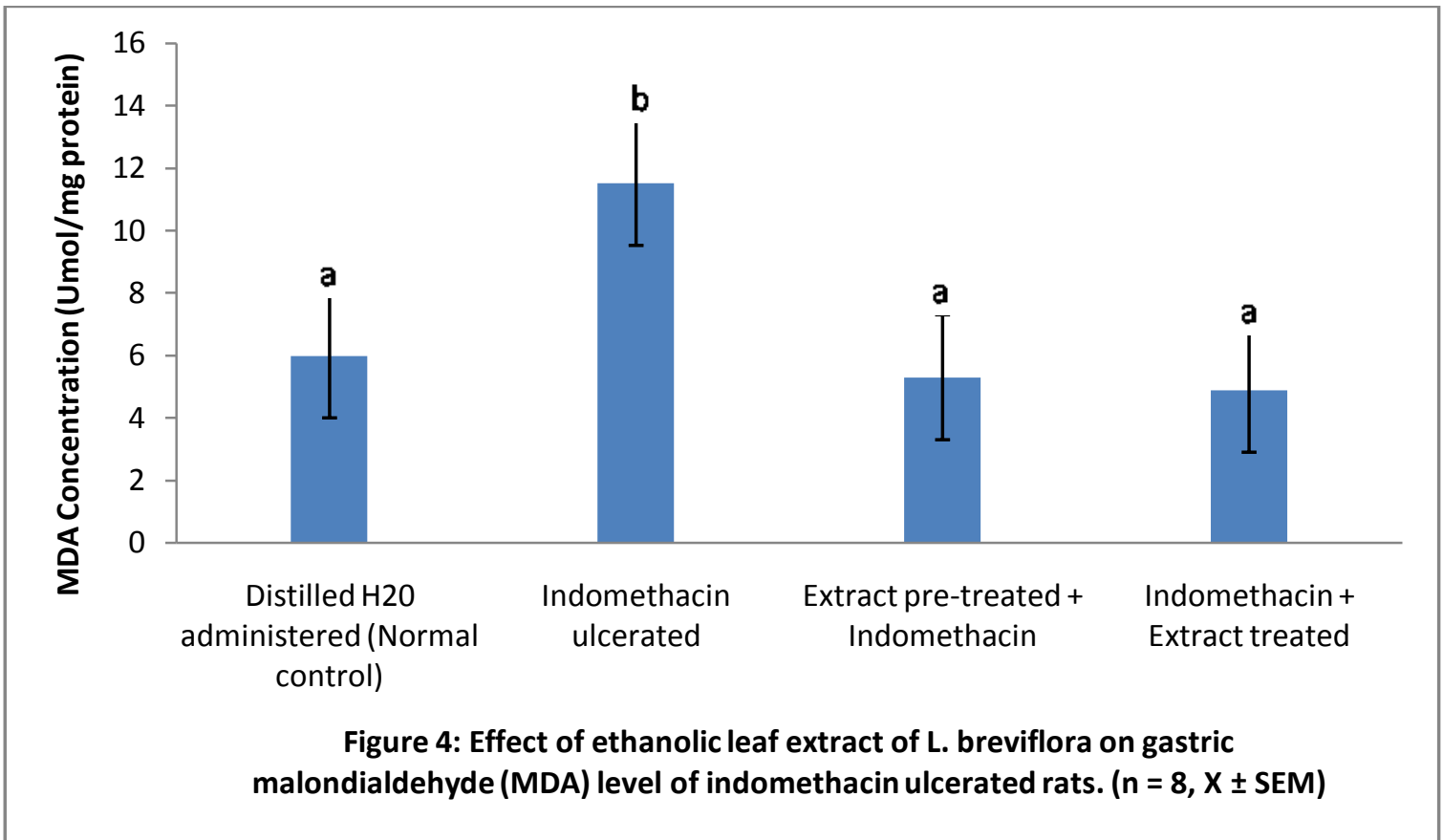

Bars with different superscripts for the parameter are significantly different $(\mathrm{P}<0.05)$. 